\title{
RESEARCH ON COMBUSTION AND EMISSIONS OF RCCI ENGINE
}

\section{CHANGCHUN $\mathrm{XU}^{1} \&$ HAENGMUKCHO ${ }^{2}, *$}

${ }^{1}$ Scholar, Department of Mechanical Engineering, Kongju National University (KNU) South Korea

${ }^{2}$ Professor, Department of Mechanical Engineering, Kongju National University (KNU), South Korea

\begin{abstract}
The RCCI (Reaction Control Compression Ignition) engine achieves very high thermal efficiency and very low NOx and low PM emissions. By mixing two fuels with different cetane numbers, reactive stratification occurs in engine cylinder to achieve reactive combustion stratification. And the fuel in the cylinder can provide combustion efficiency of the engine and reduce emissions of the exhaust. LRF (low cetane number) is injected into the cylinder after being premixed, and the HRF (high cetane number) affects pressure rise rate through segmented combustion and heat release rate, such that the segmented fuel rate of the fuel and the heat release rate can be adjusted by the two fuel injection concentrations and injection times. The CR and geometry of piston bowl of engine play an important role in this. This paper reviews the segmentation performance and injection conditions of RCCI engines and summarizes the research progress in changing combustion processes, including changes to the internal parameters of RCCI engines, includes the use of alternative fuels and the use of low-reactivity cetane number improvers. And the effect of fuel ratios with highly reactive fuels, fuel reaction strategies for different degrees of reaction, compression ratio, EGR engine performance and emission rate, and geometry of the piston bowl surface.

KEYWORDS: RCCI Engine, Bowl Geometry, Cetane Number, Compression Ratio \& Emissions
\end{abstract}

Received: Apr 01, 2020; Accepted: Apr 21, 2020; Published: Jun 09, 2020; Paper Id.: IJMPERDJUN202090

\section{INTRODUCTION}

Compared to the past, the world's engines of cars, railways, ships and jets have made global transportation more convenient. People have fully enjoyed the convenience they bring, but while they are effectively facilitated, the main components that provide power have an inevitable impact on the environment. Therefore, the research on the engine has gradually become the main research object. Therefore, in all types of engines, the CI engine field plays a crucial role, mainly because of its higher fuel efficiency [1] and higher power supply. The world's CI engines consume large amounts of fuel and subsequently burn and produce pollutants, especially in NOx and PM in exhaust emissions, which are common in conventional diesel engines because they are generated inside the cylinder during combustion. Rich in oil and lean areas, so the rich and lean oil does not affect the efficiency of the internal combustion of the engine and the exhaust emissions.

Before the RCCI engine was given some research, the HCCI engine and the PCCI engine have been studied for several decades, and preliminary results have been obtained. It can be found from the results that the use of HCCI engine and the use of PCCI engine can bring relatively high efficiency and fairly low exhaust emissions, which can effectively solve environmental pollution problems [2, 3]. Due to the high power output of the engine, high thermal efficiency and reliability of fuel use,internal combustion engines play an important role in the use of power devices. However, energy shortages and environmental pollution problems are attracting the attention of countries around the world andpromote the advancement of fuel mixed combustion technology. Therefore, the new 
internal combustion engines of HCCI, PCCI and RCCI, commonly refers to low temperature combustion, the main meaning is to achieve clean combustion and reduce exhaust emissions.

In the current research process, many researchers are focused on studying engine combustion technology and fuel injection methods and injection time control to improve the combustion process of the fuel and the combustion performance of the new engine mode. The RCCI engine is manufactured by Kokjohn et al. [4]. Reitz and Duraisamy [5] were inspired by the concept of dual-fuel HCCI engines and PCCI engine combustion during the course of the study. The study controls the combustion phasing duration and amplitude by mixing at least two different reactive (highly reactive fuels with low reactive fuels) fuel. However, these two forms of combustion are difficult to achieve under high load conditions because the heat release rate during engine combustion is controlled by the chemical kinetics of the fuel itself, which may result in unacceptable noise during the combustion process, and the high-pressure area during operation will rapidly increase the noise value. [6]. Bessonette et al. [7] Tests in heavy HCCI engines have found that the injection of two fuels has a wide range of ignition performance, and the fuel can reduce exhaust emissions in a variety of loads.

The dual fuel concept of diesel engines proposed by researchers can be discussed in 1955 [8], and the old research topics focus on how to use gaseous fuels as premixed fuels such as HG, methane and biogas [9,10]. Due to the high vaporization preheating and low carbon content, gaseous fuel can effectively reduce the emission of NOx products and PM and soot. However, Inagake et al. [11] studied the premixed CI engine of isooctane and diesel dual fuel, and met the demand for EGR. The results show that even without the action of the EGR system, the load can be expanded by adjusting the ratio of the two fuels and the injection time, thereby forming a spatial stratification of flammability and realizing stratified reaction combustion. Finally, the dual-fuel PCCI mode engine was called RCCI combustion mode engine by later researchers.Therefore, in order to achieve the minimum NOx in the exhaust emissions and the minimum smoke emission in the exhaust and maximize the thermal efficiency of the engine combustion, it is influential to adjust the fuel ratio between low-reactive fuel and high-reactive fuel the other biggest factor in engine performance is the time control during dual fuel inject. In addition to the control parameters of these RCCI engines, the structural factors of the engine also play a vital role in the combustion process of the fuel in the RCCI engine. In addition, it has been found that optimizing fuel performance is another widely recognized method for improving the combustion performance of internal fuels in internal combustion engines. Therefore, in order to fully understand the combustion of RCCI engines, this review highlights the fuel injection timing and internal engine structure of various RCCI engines. In the fuel injection research process, two fuel injection methods and single fuel injection methods with additives were summarized, and fuel characteristics were considered. High-oxygen biofuels have become a hot spot in research, as reducing soot emissions and the benefits of their use at efficient EGR rates can reduce traditional fossil fuel consumption and mitigate energy consumption crises. High oxygenated biodiesel can be divided into two types. The first class of biofuels represented by the first class of biodiesel is bioethanol. The second type of biofuel, called second generation biofuels, is made through non-edible materials and has a wide range of usability resources. In addition to the fuel ratio, in addition to the fuel ratio, and the different injection timings, the EGR usage rate, the compression ratio and the piston surface bowl geometry are also factors that fully affect the engine performance and emissions formation of the RCCI engine. However, the use of EGR to achieve to reduce NOx emissions. And due to soot occurring in the high EGR rate region, the EGR utilization rate can be affected by the emission of soot in the exhaust gas.EGR reduces the combustion temperature in the cylinder, and to a certain extent also reduces the combustion efficiency of the engine, resulting in higher $\mathrm{HC}$ and $\mathrm{CO}$ emissions, as well as relatively low NOx emissions. The LTC problem can be solved by adding an oxygenated biofuel to the diesel fuel as an additive, especially at high EGR 
rates,mainly due to the low cetane number and high oxygen content in alternative fuels. The low cetane rating of the fuel extends the prolong ignition and promotes the fuel and air mixing process. The oxygen content of the fuel primarily inhibits the production of smoke precursors by mitigating high local equivalence ratios during combustion. This makes HC and $\mathrm{CO}$ emissions reduction and makes NOx emissions increase.

Other physical properties of the fuel also play an important role in the combustion of the fuel, such as the fuel's viscosity, the point of charge, and the degree of dilution of the fuel-air mixture that also has an effect on combustion. The viscosity property of the fuel and the billing point of the fuel also play a certain role in the combustion of the fuel, effectively affecting the degree of evaporation of the fuel, sufficient mixing in the evaporation process to cause full combustion of the fuel, and high-viscosity fuel due to evaporation Failure to do so may result in an increase in fuel injection and an expected load. However, the level of the billing point can also cause the evaporation speed, thus affecting the combustion of this fuel. The mixing of fuel-air can affect the delay time of spontaneous combustion and effectively affect the emission of exhaust gas.

\section{RCCI COMBUSTION}

The RCCI engine uses a dual-fuel combustion technology, so the fuel used in the engine combustion is at least two different reaction substances (high and low) fuels to achieve mixed combustion of cylinder fuels and is controlled using multiple injection modes and appropriate EGR rates. In-cylinder reactivity to optimize combustion stage, duration and combustion intensity for high thermal efficiency and low NOx and soot emissions [5]. The structure diagram of representative combustion of RCCI engine is shown in Figure 1. The injection of low-reactivity fuel (LRF) (such as gasoline) is mainly injected into the air passage through the airport fuel injector in the intake manifold to combine with air to achieve pre-mixing of air fuel. At the same time, during the compression stroke, the highly reactive fuel diesel is injected into the cylinder through the diesel injector. The injection of high-reactivity fuel (HRF) is not done at once, but the injector is injected once, twice and three times indirectly. Combustion duration and combustion phasing are controlled by fuel properties (cetane content, oxygen content) and the fuel ratio of high-reactive fuel to low-reactive fuel, and the spatial stratification between fuels. Since the fuel injection area is the squeezing zone of the HRF, the relatively late injected HRF acts as the ignition source, and the high pressure, the pressure value of the fuel reaching the combustion causes the compression combustion of the HRF, which causes the combustion of the LRF, so the RCCI Combustion takes place [12, 49,51].

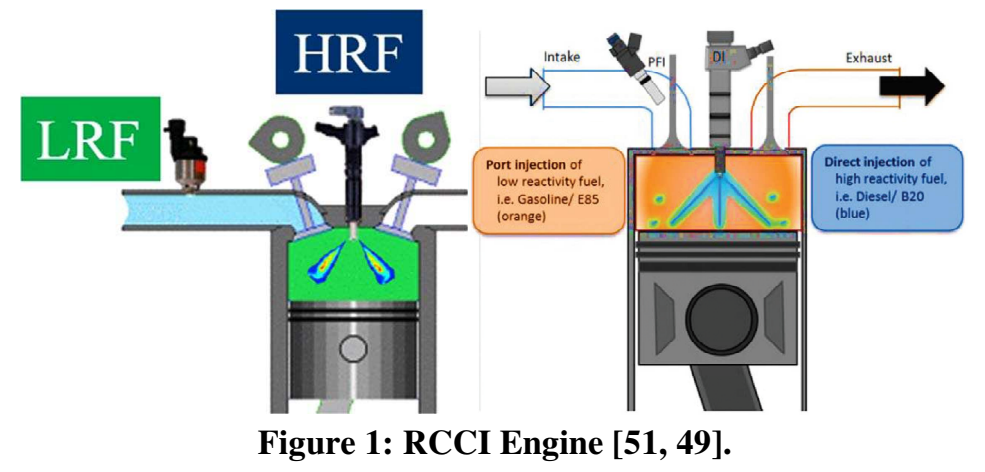

As mentioned above, RCCI combustion can be operated under various engine loads [11], When the NOx and soot contents are zero, the pressure rises and exhaust gas cycle strength, and very high indication efficiency [13, 14]. 
Kokjohn et al. [13] in the single-cylinder engine, the performance and emissions between the RCCI engine and the CDC engine were compared. It was found that the RCCI engine combustion mode can significantly reduce NOx emissions and soot emissions in the exhaust gas. Through the experimental results during the study, it was found that the RCCI engine combustion mode increased the overall combustion efficiency of the engine by $16.4 \%$.In addition, RCCI engine related research Curran et al. [15] also conducted effective tests. The same conclusion was found - the RCCI engines can effectively reduce NOx emissions. The research process is compared to a CDC engine on a four-cylinder light diesel engine. As a result, it was found that NOx was reduced, but HC and CO in the exhaust gas had an increasing tendency. In this study, the characteristics of combustion of the two engines were similar to the exhaust emissions performance, and the neat TDC injection started and controlled the stratified combustion phase of the two injection modes. However, due to the lower ignition delay of diesel caused by the lower cetane number, RCCI can provide more combustion phasing control. Yang et al. [17] alsocompare RCCI mode and hybrid fuel mode. From the results, it was found that diesel can generate $\mathrm{OH}$ radicals during the low temperature reaction, however, the oxidation of the generated $\mathrm{OH}$ radicals plays a vital role in the combustion exotherm process. Combustion from diesel to gasoline can reduce PPRR compared to the hybrid mode; lower NOx and RCCI soot are produced because the oxidation of OH radicals is reduced during fuel changes, thereby shortening the exothermic process.

\section{Fuel Mass Ratio}

The fuel ratio (e.g., mass flow, energy input or fuel input volume ratio, as a low reactivity fuel and a highly reactive fuel) affects the reactivity of the in-cylinder fuel. The reactivity of passing fuel in RCCI engine combustion mode can be roughly divided into two types: overall reactivity and stratified reactivity. [18]. The reactivity of the overall fuel is entirely dependent on the input of each fuel and the reactivity index contained within the fuel. And the reactive stratification is more in a variety of ways and is related to the injection permeability of the fuel and the amount of direct injected fuel and the contained properties of the mixture. The reactive stratification method can effectively delay the ignition time, reduce the HRR value when the fuel in the cylinder is burned, and reduce the release of PPRR. In the RCCI mode, in addition to the reaction stratification, there are certain effects, as well as the fuel equivalent ratio and temperature stratification during the reaction, which can reduce the combustion characteristics of the fuel combustion and the generation of exhaust gas emissions. For RCCI mode combustion in engine cylinders, fuel ignition is fully pre-mixed with air in the cylinder after direct injection of fuel from the low reactivity fuel, and then high reactivity (high sixteen by its HRF injection during compression) Alpha value) The fuel is first burned as an ignition source under high pressure conditions, which promotes the combustion of LRF low reactivity (high octane) fuel and causes RCCI type combustion to occur [19, 20, 21, 50]. In previous studies, the low reactivity fuels commonly used in the interior of conventional RCCI internal combustion engines include gasoline, natural gas, methanol and ethanol. At the same time, diesel/biodiesel is commonly used as a highly reactive fuel for injection reactions. Because those highly reactive fuels are mainly dependent on the characteristics of the fuel, such as fuel volatility, evaporation rate, cetane number and the like. However, the direction of the most important flame propagation depends to a large extent on the type of engine, internal structure, injection timing and injector injection angle [50]. 


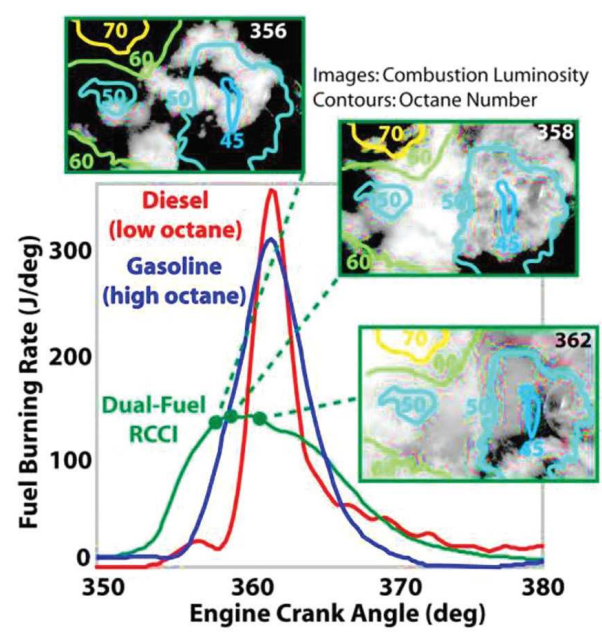

Figure 2: Reactivity for Dual-Fuel RCCI Combustion [50].

The fuel ratio can affect the fuel's reactivity and the fuel's ignition delay. Typically, the ignition delay time is related to the ratio of LRF into engine cylinder, and increases as the LRF increases. Li et al. [22] studied the effect of fuel ratio on fuel RCCI engines. The results show that NOx reduction and soot emissions increase, we can find in figure 3.

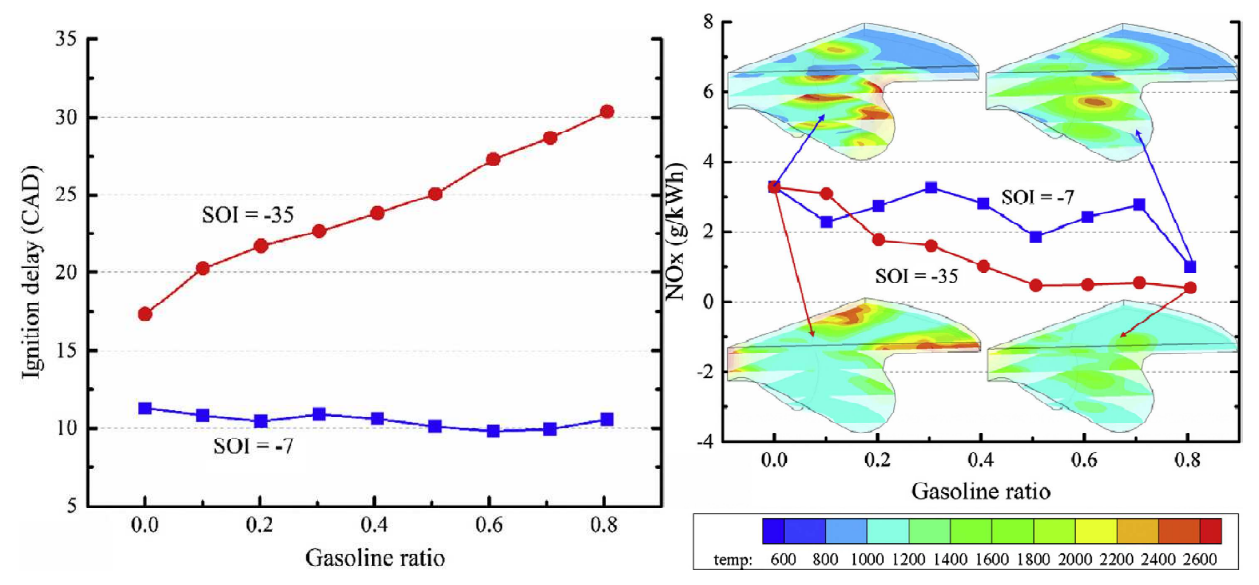

Figure 3: Different Low Reactivity Fuel Ratio with Different

Ignition Delay, and Make Emissions Reduction [22].

Under normal conditions, when the fuel ratio is changed in the experiment, the reaction in the cylinder will change. Different fuel ratios can affect the ignition delay of the fuel.Generally, as the ratio of LRF increases, the ignition delay time will increase. However, it is important that the engine-specific specifications and the experimental conditions set during the experiment also affect the ignition delay during fuel combustion. Therefore, in the results, as the LRF fuel input ratio increases, some studies have found that engine performance can be improved, but other studies can also find that engine performance has decreased. The reason for this opposite observation is that we can speculate that the reason may be that the engine specifications used in the experiment are different,SOI time and fuel combustion characteristics. The increased LRF is advantageous over the effect on NOx emissions. As the LRF ratio increases, the low temperature combustion indicated by the PPRR can reduce NOx emissions.

\section{Fuel Strategy}

The fuel injection method is a crucial issue in the research of RCCI engines, because the fuel injection method leads to the 
combustion performance of the engine and the influence of fuel reactivity stratification. Over the years, researcher has studied different combinations of various fuels like low and high reactivity fuels. RCCI engine fuel injection before combustion is defined as two types: dual fuel injection strategy and single fuel injection strategy. The single fuel injection strategy, as the name implies, only one type of fuel is injected into the cylinder, and mixed air combustion is performed in the cylinder. However, the dual fuel injection strategy means that two types of fuel are injected into the cylinder, and the difference in the properties of the two fuels is used to produce a difference in reactivity, thereby meeting the combustion requirements of the engine's mixed fuel. However, due to the need to inject two fuels, this strategy requires the addition of two fuel tanks to the RCCI internal combustion engine-guided vehicle as an injection device. We usually pursue the lightweight type of the car, the space inside the car and the fuel saving. Therefore, due to various reasons, the injection strategy of the single fuel is mainly studied, mainly by adding some additives to change the reactivity of the fuel to consider a single the fuel strategy, which allows the additive to mix with the original fuel, creates a reactive difference. However, in this section we can discuss the state of use of the two fueling strategies（high and low reactivity fuel） added to the RCCI internal combustion engine.

\section{Low Reactivity Fuel}

Table 1: Fuel Properties of Low Reactivity Fuel in Engine[23, 51]

\begin{tabular}{|l|c|c|c|c|}
\hline \multicolumn{1}{|c|}{ Property } & Gasoline & NG & Methanol & Ethanol \\
\hline Chemical formula & $\mathrm{C} 8 \mathrm{H} 15$ & $\mathrm{CH} 4$ & $\mathrm{CH} 3 \mathrm{OH}$ & $\mathrm{C} 2 \mathrm{H} 5 \mathrm{OH}$ \\
\hline Molecular weight(g/mol) & 111 & 16 & 32 & 46 \\
\hline Heat of vaporization(kJ/kg) & 307 & 509 & 1147 & 873 \\
\hline Higher heating value(MJ/kg) & 47.3 & 55.26 & 22.54 & 29.71 \\
\hline Lower heating value(MJ/kg) & 43 & 49.77 & 20.05 & 26.95 \\
\hline Stoichiometric air/fuel ratio & 14.6 & 17.2 & 6.5 & 9 \\
\hline Research Octane Number(RON) & $92-99$ & 120 & 92 & 89 \\
\hline Motor octane number (MON) & $80-91$ & 120 & 106 & 107 \\
\hline Cetane number & $14.5-20$ & 0 & 7 & 6.5 \\
\hline
\end{tabular}

Table 1 lists the attribute of the fuel selected as the LRF in the RCCI engine. In the table, the cetane number is calculated based on equation (1) [11]

$$
\mathrm{CN}=\frac{120-R O N}{2}
$$

$\mathrm{CN}$ is a fuel's cetane number; RON is fuel's octane number for studying.

Compared to gasoline, NG, methanol and ethanol produce a larger reaction gradient at the same HRF. Among 
these three alternative fuels, methanol fuel and ethanol fuel can play a role in reducing combustion temperature and increasing fuel oxygen content in the cylinder, mainly because of their high vaporization latent heat and high oxygen content, which helps the engine to burn, reduce NOx and soot emissions, and these emissions are increased due to the energy density of alcohol fuel, because the heating value of methanol and ethanol is low, resulting in higher fuel consumption.

\section{High Reactivity Fuel}

Commonly used HRFs are diesel/biodiesel. Diesel is a petroleum-based fuel that cannot be used in transition because oil is a non-renewable fuel. Oil production worldwide is steadily decreasing. According to reports, known oil reserves may be exhausted after many years. As a result, many countries face energy shortages and oil dependence, so the priority now is to find some fuels that can replace oil. Through the unremitting efforts of researchers, we have discovered a fuel that can replace petroleum - biofuels.

Biodiesel refers to fatty acid methyl esters or ethyl esters made from plant tree seeds, plant edible oils or animal fats through a certain chemical reaction, and its properties are similar to those of diesel, so biodiesel can be applied to diesel engines [27]. Biodiesel can also be produced by processing non-edible materials, such as non-edible vegetable fats, waste edible oils and animal fats. Therefore, the required characteristics of biodiesel are controlled by the source of biodiesel and its own quality. The different characteristics of biodiesel itself can affect the characteristics of combustion and the emission of exhaust gas. The chemical and physical characteristics of fuel are the most important. Different biofuel properties contribute to the different combustion properties of the engine, so in recent decades researchers have tested engines relative to the use of various biodiesel. Thus, biofuels suitable for internal combustion engines were adjusted and found. The test results showed that due to the oxygen content is higher contained in the biofuels than pure fuels, the NOx in the diesel engines used for biodiesel fuels were observed to increase through oxidation reactions [28, 29]. Li et al. [22] numerical studies show that gasoline/biodiesel emissions are lower than pure biodiesel fuels. The results show that gasoline/biodiesel used in RCCI engines can reduce nitrogen oxide emissions compared to diesel engines that use pure biodiesel as fuel, like Figure 3 shown.

\section{EGR Rate}

Interestingly, the possibility of using EGR has been raised when exploring the RCCI internal combustion engine to reduce emissions from CI engines [11, 19]. EGR utilization has a certain impact on engine performance and emissions 
formation. The use of exhaust gas recirculation into the cylinder to reduce the intake of air further reduces the oxygen content of the fuel, thereby changing the exhaust emissions. [30, 31]. In addition, emissions of nitrogen oxides and soot have also decreased $[30,31,32,33]$. This is due to the decrease in combustion temperature in the cylinder, mainly due to the dilution and thermal effect of EGR, which causes the nitrogen substances to not react, thereby reducing the reduction of nitrogen oxides [34]. Therefore, in summary, the reduction of NOx and soot can be attributed to the low temperature combustion and the reduction of oxygen-containing substances. [35].In most studies, as EGR increases, UHC and CO emissions increase. This is because the EGR rate increases to reduce the oxygen concentration in the cylinder, resulting in insufficient response in the local rich zone, which in turn causes incomplete oxidation of fuel. Therefore, $\mathrm{HC}$ and $\mathrm{CO}$ emissions have increased.

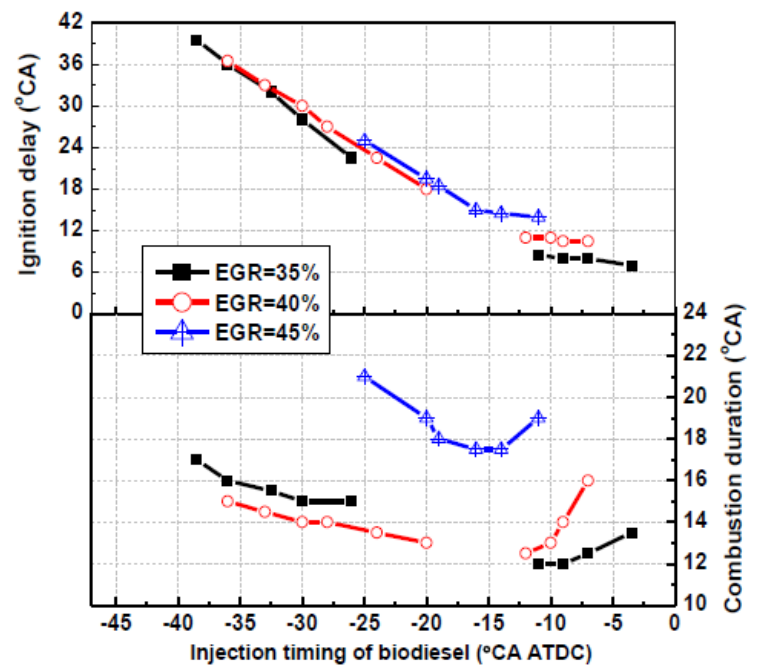

Figure 4: The Ignition Delay with Combustion Duration Under Various EGR Rates [32].

Wu et al. [36] also studied the EGR rate's effect on engine performance and emissions. Obviously, PPR, NOx and soot emissions can be reduced by increasing the EGR rate. And, in addition to this research, Akihama et al. [38] low NOx and soot emissions levels have also been studied, primarily because of the low combustion temperatures of the in-cylinder fuel.

$\mathrm{Li}$ et al.[22] EGR is used in medium-sized applications of RCCI engines driven by methanol and diesel. It was concluded that the necessity of using EGR depends on the initial temperature of the fuel injected entering the cylinder.If the initial temperature of the injected fuel is below the critical value, there is no need to use EGR, and methanol can be manually diverted to maintain the combustion performance of the engine. In addition, although a cooled EGR system can reduce NOx emissions, it comes at the cost of higher soot and UHC emissions. Yu et al. [39] further confirmed this claim through experimental research show us figure 5 .

The emission characteristics and EGR rate of the RCCI and mixed fuel modes are shown in figure 5 [39]. As can be seen from figure 5 (a) below, all combustion modes exhibit soot emissions and nitrogen oxide emission characteristics. From the results shown in the figure, it can be seen that the increase in smoke emissions is similar to the increase in nitrogen oxides. The sequence of soot emissions can be found as follows: pure biodiesel > RCCI > mixed fuel mode, RCCI internal combustion engine combustion mode andMixed fuel combustion can effectively improve smoke emissions and NOx emissions compared to pure biodiesel combustion mode, especially in efficient Below the EGR rate, the RCCI mixed 
fuel mode produces only nitrogen oxides, and the amount produced is very rare. Figure 5(b) shows the CO and HC emission characteristics. It can be seen from the data that the pure biodiesel and blended fuel modes show relatively low CO emissions when the EGR rate is increased to 50\%, and the EGR rates are $0 \%$ and $30 \%$ for EGR rates of $0 \%$ and $30 \%$. $\mathrm{HC}$ and $\mathrm{CO}$ emissions are very small. However, in the RCCI combustion mode, 50\% high EGR rate, CO and HC emissions rose sharply. Compared with $0 \%$ and 50\% EGR usage rates, RCCI combustion mode can achieve low carbon monoxide and hydrocarbon emissions at 30\% EGR rate. As we all know, the EGR system can reduce the combustion temperature and prolong the ignition delay, which is positive and effective for reducing NOx emissions, but it is harmful to the oxidation of soot. Therefore, the higher EGR rate used will result in higher emissions and low NOx emissions. At high oxygen levels, volatile matter and more premix content produce much lower soot at high EGR rates. At low EGR rates, higher combustion temperatures resulting from higher heat release rates will result in higher NOx emissions than RCCI.
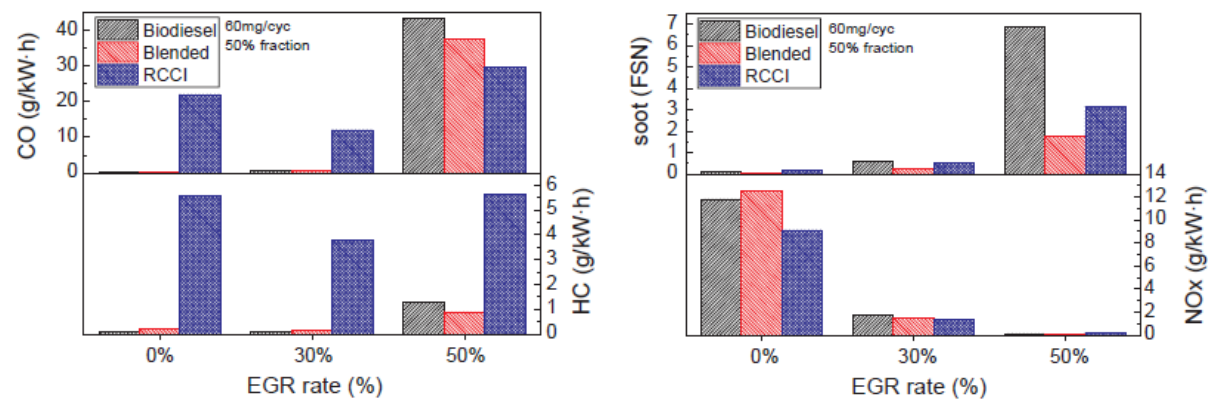

Figure 5: Emission Characteristics of Dual Fuel RCCI and Blended Fuel Mode at Different EGR Rates [39].

\section{Compression Ratio}

The compression ratio of the engine is one of the important parameters that affect the efficiency of the engine.Dempsey et al. [40] the RCCI engine with acompression ratio of 11.7 was optimized to achieve a certain extended operating load. Jia and Denbratt [41] studied the combustion experiments of RCCI engines with different compression ratios of natural gas / diesel dual fuel were studied and analyzed, and engines with different compression ratios were also tested at different engine speeds. It was found from experiments that the difference in compression ratio also affects the temperature of the EGR system.Since the combustion rate of the low CR 14 fuel is slow, the combustion period is prolonged, resulting in the EGR temperature of the CR 14 being higher than the combustion temperature of the high CR 17, but the thermal efficiency of the CR 14 is higher than the thermal efficiency of the CR 17; however, the generation of thermal efficiency in the total stroke load of the engine is also constant. When the engine speed is increased to $1800 \mathrm{rpm}$, higher thermal efficiency can be observed at CR17. Considering the emission of exhaust gas from CR 14, NOx is reduced compared to CR 17, but UHC is increased, which mainly depends on different compression ratios (CR). In addition, the combustion characteristics of engines with a compression ratio of 14 and a compression ratio of 17 under different loads are compared. The conclusion is that an engine with a compression ratio of 14 produces a longer ignition delay, combustion duration and lower maximum heat release rate.Therefore, due to the PPRR limitation caused by the internal structure of the engine, CR 14 is particularly suitable for the research of RCCI internal combustion engines under high load.

In this study, we can draw on the study of Suozhu Pan et al. [43]. In this study, the in-cylinder pressure of the CCM and 2-butanol / diesel dual-fuel RCCI internal combustion engine and the RoHR in the engine were compared with each other, and their loads were set at 50\% and 100\%, as shown in Figure 6.As shown in Fig. 6, the maximum in-cylinder 
pressure in RCCI combustion mode and the RoHR value in RCCI combustion mode are significantly higher than the in-cylinder pressure values in RoHR and CCM combustion mode in CCM combustion mode. And RoHR increases as the premixed air-fuel ratio of the injection amount of the low-reactivity fuel 2-butanol increases. The trend has become more pronounced (because the high oxygen content itself promotes rapid combustion and higher latent heat). First, the RCCI mode of operation reduces the amount of highly reactive diesel fuel injected, which reduces the reactivity. Secondly, when the low latent fuel 2-butanol contains a relatively high latent heat, it is necessary to absorb more heat,therefore, during the compression stroke of the internal combustion engine, the intake air may result in a lower in-cylinder combustion temperature. These factors can inhibit the pressure in the cylinder during the in-cylinder compression stroke from causing compression ignition suppression within the cylinder, resulting in a higher ignition delay, which will result in more fuel for premixing combustion and increased fuel consumption. In addition, 2-butanol contains a higher molecular oxygen content that accelerates the rate of combustion and releases heat faster. This important factor also promotes the increase in the peak pressure in the cylinder and the output of the maximum value of RoHR. [43].

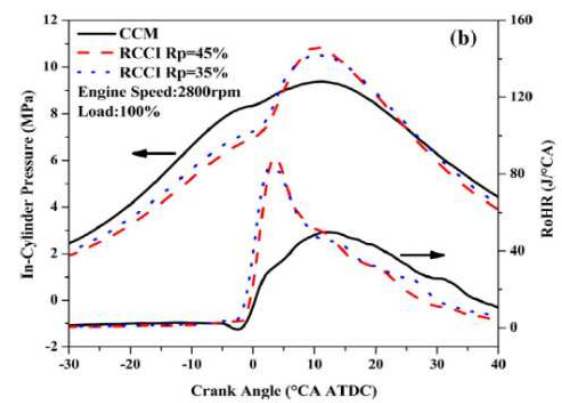

Figure 6: In-Cylinder Pressure and RoHR for 2-Butanol / Diesel RCCI Operation at $50 \%$ (a) and $100 \%$ (b) Loads[43].

\section{Bowl Geometries}

The geometries of the engine piston bowl is another important structural parameter affecting the RCCI internal combustion engine, which can effectively affect the premixing process between air and fuel and can then effectively affect the combustion process [14]. Pistons designed for conventional diesel engines are used for hybrid control combustion [44]. For RCCI combustion, it is considered that Most of LRF's fuel has been fully pre-mixed with air; therefore, researchers have considered developing suitable pistons for premixed fuels. In addition, the surface area of the engine cylinder also affects the heat transfer and heat dissipation process during fuel combustion as well as the pressure and heat release values (shown Figure 8) in the cylinder [45, 46]. Li et al. [44, 45]Influence of Piston Bowl Geometry on High-load RCCI Engines driven by biodiesel and gasoline was investigated. The bowl geometry of the piston surface studied was hemispherical combustion chamber, shallow combustion chamber and Omega combustion chamber,as shown in figure7. According to research data, the OCC design of the diesel engine is better suited to engine combustion, thereby controlling the fuel mix ratio to control the combustion phase. On the other hand, SCC is well suited for RCCI because the RCCI engine can fully realize the efficient combustion characteristics and performance of the internal fuel of the engine under the low NO, CO and soot emission levels. 


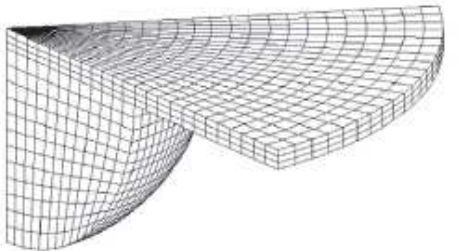

(a) $\mathrm{HCC}$

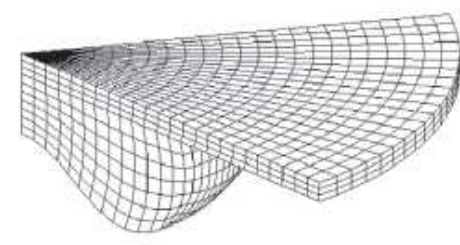

(b) SCC

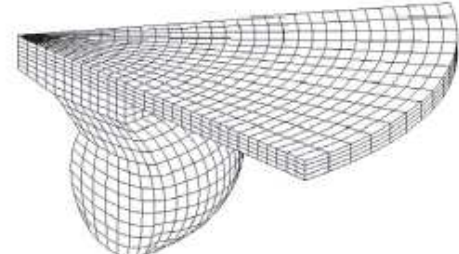

(c) $\mathrm{OCC}$

Figure7: Piston Bowl Geometries[44,45].

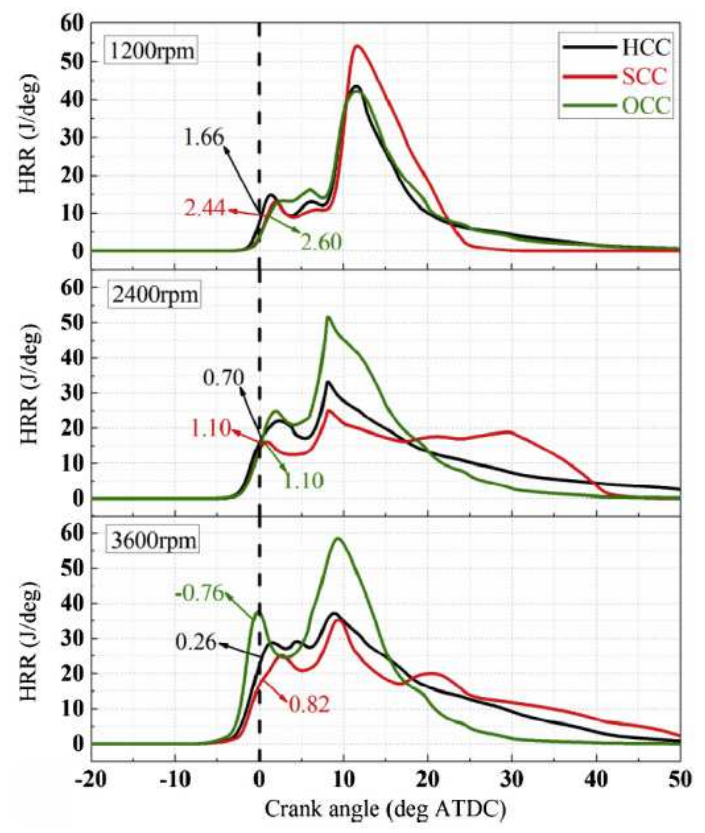

Figure 8: HRR at Various Engine Speeds

Under Medium Load [45].

Splitter et al. [47] optimized the shape of the piston of the premixed fuel. In order to reduce the heat transfer during the combustion process, the volume ratio of the cylinder is reduced. Importantly, a reduction in the ratio of the surface area to volume of the piston bowl of the RCCI engine will significantly increase the throat diameter of the bowl, but it will affect the reduction in heat transfer. An effective method can advance the SOI time of the RCCI engine injection strategy. [44].In order to improve the combustion efficiency, that is, to reduce the emissions of $\mathrm{HC}$ and $\mathrm{CO}$, the complete combustion of fuel in the cylinder is increased[26]. Figure 7shows the geometry of three test bowls. The experimental results show that with this newly designed piston bowl geometry and the latest optimized fuel injection strategy, RCCI's brake thermal efficiency can be increased from $37 \%$ to $40 \%$ at a speed of $2600 \mathrm{rpm}$ and an injection pressure of 6.9 bar. At the same time, NOx and PM emissions are within specified limits and no exhaust gas aftertreatment is required.

Benajes et al. [48] compared three types of bowl shapes, namely stocks, ladders and bathtubs, as shown in Figures 9 and 10. These pistons were tested at low, medium and high loads using a single injection and dual injection strategy. Under low load conditions, the spare piston can promote the ignition point of the premix of air and fuel. In addition, the three injection methods used in the implementation process can achieve low emissions of NOx and soot.Under moderate load, the performance and emissions of stepped pistons are very similar to those of ordinary pistons; conversely, under high loads, stepped pistons show better results than the other two geometries. Finally, the results are obtained through 
experiments. Among the three types of piston structures in the experiment, the structure of stepped pistons is found to be the most suitable for RCCI engines and to effectively promote combustion, especially considering that RCCI combustion can be changed at any time.

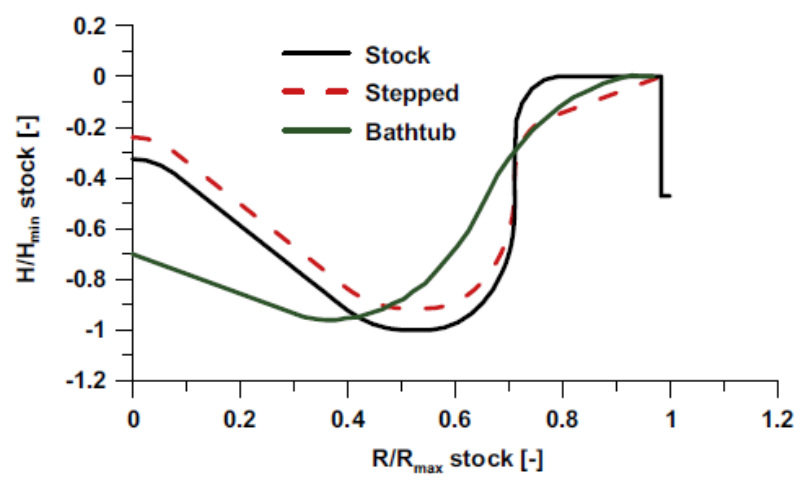

Figure 9: Three Types of Piston bowl (a) Stepped (b) Bathtab (c) Stock [48, 51].
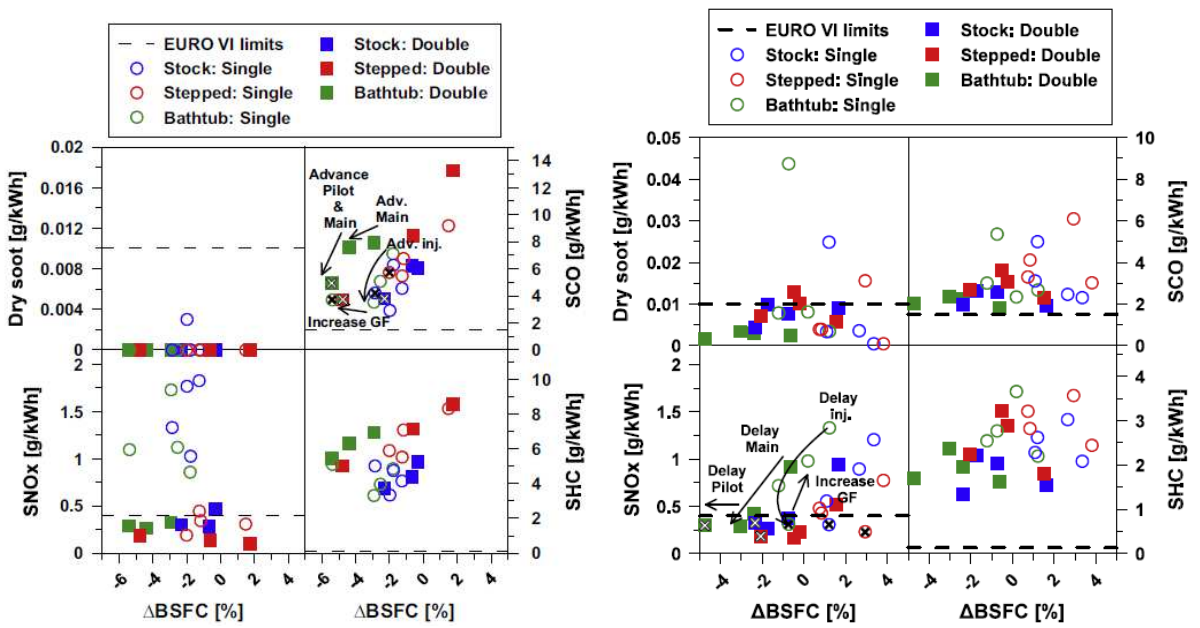

Low Load Medium Load

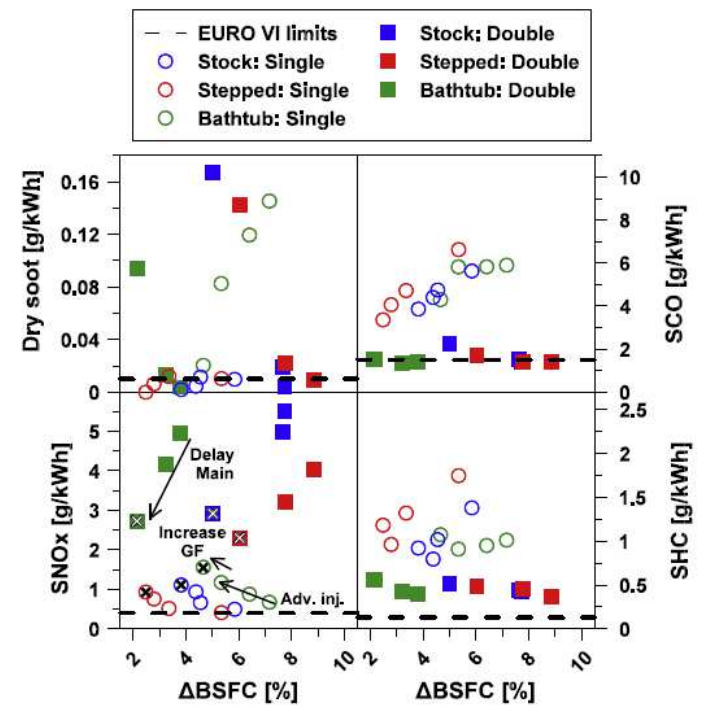

High Load

Figure 10: Emissions at Different Loads with Three Type Piston Geometries [48]. 


\section{CONCLUSIONS}

This article summarizes that RCCI is a combustion mode. Two fuels are used in the cylinder for mixed combustion, and a reactive gradient combustion occurs between the two fuels, which can effectively control the combustion phasing and maintain the pressure increase rate. Therefore, optimized RCCI combustion results in high thermal efficiency of the engine and low NOx and PM emissions.

This paper discusses the management of fuel injection in RCCI engines from two aspects: the characteristics of the fuel itself and the parameters of the internal structure of the controllable engine.

In addition, an additive which can improve the cetane number (i.e., reactivity) of the fuel is added, thereby considering the injection method of the LRF fuel; therefore, the LRCI / LRF additive combination is applicable to the RCCI engine.

Regarding the engine research, the fuel ratio, injection timing, split injection amount, EGR rate, CR and the shape of the piston bowl shape of the high and low reactive fuel injection are also discussed. Increasing the combustion ratio of LRF fuel can reduce NOx and soot emissions. The increase in EGR rate is one of the effective methods to reduce the combustion temperature in the cylinder to reduce the formation of NOx.The RCCI engine has also tested and studied whether improving the internal structure of the engine can promote engine performance and emissions. That is to change the shape of the piston bowl and change the $\mathrm{CR}$ of the engine. The choice of bowl shape depends on how to reduce heat loss. Low CR can extend the engine load.

\section{ACKNOWLEDGMENT}

This work was supported by the National Research Foundation of Korea (NRF) grant funded by the Korea government (MSIT) (NRF-2019R1A2C1010557).

\section{REFERENCES}

1. Reitz, RD. Directions in internal combustion engine research. Combust Flame 2013; 160:1-8.

2. Epping K, Aceves S, Bechtold R, Dec J. The potential of HCCI combustion for high efficiency and low emissions. Training 2002; 2013, 11-04.

3. Kanda T, Hakozaki T, Uchimoto T, Hatano J, Kitayama N, Sono H. PCCI operation with early injection of conventional diesel fuel. SAE Trans 2005;114:584-93.

4. Kokjohn, S.L., Hanson, R. M., Splitter, D.A. \& Reitz, R.D. 2010. Fuel reactivity controlled compression ignition (RCCI): a pathway to controlled high-efficiency clean combustion. International Journal of Engine Research 12(3):209-226.

5. LAKSHMAN, R., and A. Ramesh. "A System Dynamic Analysis of Energy Consumption and CO2 Emission of Indian Iron and Steel Industries." International Journal of Mechanical Engineering 3.4 (2014): 49-60.

6. Reitz, R.D \&Duraisamy, G. 2015. Review of high efficiency and clean reactivity controlled compression ignition (RCCI) combustion in internal combustion engines. Progress in Energy and Combustion Sciences 46: 12-71. 
7. Lu X, Han D, Huang Z. Fuel design and management for the control of advanced compression- ignition combustion modes. Prog Energy Combust 2011; 37; 741-83.

8. Sampatrao, DAINGADE AJIT, Metkari Ganesh Sunil, and P. D. Kulkarni. "Performance \& Emission Analysis of Biodiesel Using Various Blends (Castor Oil+ Neem Oil Biodiesel)." Impact Journal, 2, 117123 (2014).

9. Bessonette P, Schleyer C, Duffy K, Hardy W, Liechty M. Effects of fuel property changes on heavy-duty HCCI combustion. Polymer 2007; 2013:04-8.

10. Karim GA. A review of combustion processes in the dual fuel engine-the gas diesel engine. Prog Energy Combust $1980 ; 6 ; 277-85$.

11. AbdAlla GH, Soloman HA, Badr OA. AbdRabbo MF. Effect of injection timing on the performance of a dual fuel engine. Energy Convers Manag 2002; 43:269-77.

12. Sahoo BB, Sahoo N, Saha UK. Effect of engine parameters and type of gaseous fuel on the performance of dual-fuel gas diesel engines- a critical review, Renew Sust Energy Rev 2009;13:1151-84.

13. Inagaki K, Fuyuto T, Nishikawa K, Nakakita K. Dual-fuel PCI combustion controlled by in-cylinder stratification of ignitability. SAE Technical Paper 2006-01-0028; 2006.

14. Eichmeier JU, Reitz RD, Rutland C. A zero-dimensional phenomenological model for RCCI combustion using reaction kinetics. SAE Int J Engine 2014;7:106-19.

15. Krishna, MVS Murali, and K. Vamsi Krishna. "Studies on Exhaust Emissions of Di Diesel Engine with Low Grade LHR Combustion Chamber Fuelled with Linseed Biodiesel." International Journal of Mechanical Engineering (IJME) 3.6 (2013): $63-72$.

16. Kokjohn SL, Hanson RM, Splitter DA, Reitz RD. Fuel reactivity controlled compression ignition (RCCI): a pathway to controlled high-efficiency clean combustion. Int J Engine Res 2011;12:209-26.

17. Kokjohn SL, Reitz RD. Reactivity controlled compression ignition and conventional diesel combustion: a comparison of methods to meet light-duty NOx and fuel economy targets. Int J Engine Res 2013;14:452-68.

18. Curran SJ, Hanson RM, Wagner RM. Reactivity controlled compression ignition combustion on a multi-cylinder light-duty diesel engine. Int J Engine Res 2012;13:216-25.

19. Kavuri, C., Paz, J. \&Kokjohn, S.L. 2016. A comparison of Reactivity Controlled Compression Ignition (RCCI) and Gasoline Compression Ignition (GCI) strategies at high load, low speed conditions. Energy Conversion and Management 127: $324-341$.

20. Yang B, Yao M, Cheng WK, Li Y, Zheng Z, Li S. Experimental and numerical study on different dual-fuel combustion modes 
fuelled with gasoline and diesel. Appl Energy 2014;113:722-33.

21. Li J, Yang WM, Goh TN, An H, Maghbouli A. Study on RCCI (reactivity controlled compression ignition) engine by means of statistical experimental design. Energy 2014;78:777-87.

22. Rao, B. Subba, et al. "Studies on exhaust emissions and combustion characteristics of tobacco seed oil in crude form and biodiesel from a high grade low heat rejection diesel engine." International Journal of Industrial Engineering and Technology 3.1 (2013): 27-36.

23. Kokjohn SL, Hanson RM, Splitter DA, Reitz RD. Experiments and modeling of dual-fuel HCCI and PCCI combustion using in-cylinder fuel blending. SAE Int J Engine 2010; 2:24-39.

24. Kokjohn SL, Musculus MPB, Reitz RD. Evaluating temperature and fuel stratification for heat-release rate control in a reactivity-controlled compression-ignition engine using optical diagnostics and chemical kinetics modeling. Combust Flame $2015 ; 162: 2729-42$.

25. Splitter D, Kokjohn S, Rein K, Hanson R, Sanders S, Reitz R. An optical investigation of ignition processes in fuel reactivity controlled PCCI combustion. SAE Int J Engine 2010; 3:142-62.

26. Li, J., Yang, W.M., An, H. \& Zhao, D. 2015. Effects of fuel ratio and injection timing on gasoline/biodiesel fueled RCCI engine: A modeling study. Applied Energy 155:59-67.

27. Pulkrabek WW. Engineering fundamentals of the internal combustion engine, $2^{\text {nd }}$ ed. Prentice Hall; 2003.

28. Ryan Walker N, Wissink ML, DelVescovo DA, Reitz RD. Natural gas for high load dual-fuel reactivity controlled compression ignition in heavy-duty engines. JEnergyResourTechnol2015;137:042202-.

29. Dempsey AB, Walker NR, Reitz R. Effect of piston bowl geometry on dual fuel reactivity controlled compression ignition (RCCI) in a light-duty engine operated with gasoline/diesel and methanol/diesel. SAE Int J Engine 2013; 6:78-100.

30. Hanson R, Curran S, Wagner R, Reitz RD. Effects of biofuel blends on RCCI combustion in a light-duty, multi-cylinder diesel engine. SAE Technical Paper 2013-01-1653; 2013.

31. Lapuerta M, Armas O, Rodríguez-Fernández J. Effect of biodiesel fuels on diesel engine emissions. Prog Energy Combust 2008; 34:198-223.

32. Vallinayagam R, Vedharaj S, Yang WM, Lee PS, Chua KJE, Chou SK. Combustion performance and emission characteristics study of pine oil in a diesel engine. Energy 2013; 57:344-51.

33. Vedharaj S, Vallinayagam R, Yang WM, Chou SK, Chua KJE, Lee PS. Experimental investigation of kapok (Ceibapentandra) oil biodiesel as an alternate fuel for diesel engine. Energy Convers Manag 2013; 75:773-9. 
34. Wu Y, Reitz RD. Effects of exhaust gas recirculation and boost pressure on reactivity controlled compression ignition engine at high load operating conditions. J Energy ResourTechnol 2015; 137:032210.

35. Yu C, Wang J, Yu W, Liu J, Gao D. Research on low temperature combustion of homogeneous charge induced ignition (HCII) in a light-duty diesel engine. In: Proceedings of the FISITA 2012 world automotive congress. Springer; 2013. p.195-204.

36. Liu H, Wang X, Zheng Z, Gu J, Wang H, Yao M. Experimental and simulation investigation of the combustion characteristics and emissions using n-butanol/biodiesel dual-fuel injection on a diesel engine. Energy 2014.

37. Ma S, Zheng Z, Liu H, Zhang Q, Yao M. Experimental investigation of the effects of diesel injection strategy on gasoline/diesel dual-fuel combustion. Appl Energy 2013; 109:202-12.

38. Ladommatos $\mathrm{N}$, Adelhalim $\mathrm{S}$, Zhao $\mathrm{H}, \mathrm{Hu} \mathrm{Z}$. The effects of carbon dioxide in exhaust gas recirculation on diesel engine emissions. ProcInstMechEng. Pt D J AutomobEng 1998; 212:25-42.

39. Akihama K, Takatori Y, Inagaki K, Sasaki S, Dean AM. Mechanism of the smokeless rich diesel combustion by reducing temperature. SAE Technical Paper 2001-01-0655; 2001.

40. Wang, Y., Zhu, Z., Yao, M., Li, T., Zhang, W. \& Zheng, Z. 2016. An investigation into the RCCI engine operation under low load and its achievable operational range at different engine speeds. Energy Conversion andManagement 124: 399-413.

41. Akihama, K., Takatori, Y., Inagaki, K., Sasaki, S. \& Dean, A.M. 2001. Mechanism of the smokeless rich diesel combustion by reducing temperature. SAE Technical Paper 2001-01-655.

42. Yu C, Wang J, Yu W, Liu J, Gao D. Research on low temperature combustion of homogeneous charge induced ignition (HCII) in a light-duty diesel engine. In: Proceedings of the FISITA 2012 world automotive congress. Springer; 2013. p. 195-204.

43. Zunqing Zheng, Mingtao Xia, Haifeng Liu $\square$, Ran Shang, Guixiang Ma, Mingfa Yao. Experimental study on combustion and emissions of n-butanol/biodiesel under both blended fuel mode and dual fuel RCCI mode. Fuel 226 (2018) 240-251.

44. Dempsey AB, Reitz RD. Computational optimization of reactivity controlled compression ignition in a heavy-duty engine with ultra low compression ratio. SAE Int J Engine 2011; 4(2222):239.

45. Jia Z, Denbratt I. Experimental investigation of natural gas-diesel dual-fuel RCCI in a heavy-duty engine. SAE Technical Paper 2015-01-0838; 2015.

46. Hanson RM, Kokjohn SL, Splitter DA, Reitz RD. An experimental investigation of fuel reactivity controlled PCCI combustion in a heavy-duty engine. SAE Int J Engine 2010; 3:700-16.

47. Suozhu Pan, Xin Li, Weiqiang Han $\square$, Yaxing Huang. An experimental investigation on multi-cylinder RCCI engine fueled with 2-butanol/diesel. Energy Conversion and Management 154 (2017) 92-101. 
48. Li J, Yang WM, Zhou DZ. Modeling study on the effect of piston bowl geometries in a gasoline/biodiesel fueled RCCI engine at high speed. Energy Convers Manag 2016; 112:359-68.

49. Li J, Yang W, An H, Maghbouli A, Chou S. Effects of piston bowl geometry on combustion and emission characteristics of biodiesel fueled diesel engines. Fuel 2014; 120:66-73.

50. Dolak J, Reitz R. Optimization of the piston geometry of a diesel engine using a two-spray-angle nozzle. ProcInstMechEng. Pt D J AutomobEng 2011; 225:406-21.

51. Splitter D, Wissink M, Kokjohn S, Reitz R. Effect of compression ratio and piston geometry on RCCI load limits and efficiency. SAE Technical Paper 2012-01-0383; 2012.

52. Benajes J, Pastor JV, García A, Monsalve-Serrano J. An experimental investigation on the influence of piston bowl geometry on RCCI performance and emissions in a heavy-duty engine. Energy Convers Manag 2015; 103:1019-30.

53. Prikhodko V, Gao Z, Curran SJ, Daw CS, Wagner RMand Parks JE. Modeling emissions control for RCCIengines. Presented at ERC 2013 symposium, University ofWisconsin-Madison, Madison, WI, June 2013.

54. Ryan TW and Callahan TJ. Homogeneous charge compressionignition of diesel fuel. SAE technical paper961160, 1996.

55. Jing Li, Wenming Yang, Dezhi Zhou. Review on the management of RCCI engines.Renewable and Sustainable Energy Reviews 69 (2017) 65-79. 

